Over 10 years ago we were able, in six consecutive cases, to demonstrate a deficiency in salivary (secretory) IgA. This deficiency did not relate necessarily to low serum IgA concentrations. In these cases sialectasis was not demonstrated and, indeed, appears to be very rare in early well treated disease. It appears to be secondary to recurrent infection. The last child we saw who required parotidectomy was seen in 1960.

In our practice recurrent parotitis has become much less common; this may reflect a change in the pattern of referrals. We recommend that the secretory IgA concentrations are estimated in cases of 'idiopathic' recurrent parotitis. Once the low IgA value is demonstrated, low dose antibiotic cover or prophylactic administration early in an attack is logical and advisable, if damage to the parotid is to be avoided.

$$
\begin{array}{r}
\text { J O N LAWSON } \\
\text { I49 Harley Street, } \\
\text { London WIN IHG } \\
\text { J R HOBBS } \\
\text { Department of Immunology, } \\
\text { Charing Cross and Westminster Medical School, } \\
\text { London SWIP } 2 A R
\end{array}
$$

1 Cohen HA, Gross S, Nussinovitch M, Frydman M, Varsano I. Recurrent parotitis. Arch Dis Child 1992; 67: 1036-7.

\section{Paediatric outpatient utilisation in a district general hospital}

EDITOR,-In their article on paediatric out- patient utilisation in a district general hospital,' MacFaul and Long cited my own research in this field which was presented to the British Paediatric Association in 1989. My data included detailed information on the referral process and outcome in addition to utilisation data. Those wishing to compare the studies will find my results reported in full in Public Health. ${ }^{2}$

C M NI BHROLCHAIN The Child Development Centre,
Northampton General Hospital,
Billing Road,
Northampton NN1 5BD

1 MacFaul R, Long R. Paediatric outpatient utilisation in a district general hospital. Arch Dis Child 1992; 67: 1068-72.

$2 \mathrm{Ni}$ Bhrolchain CM. A district survey of 1992; 106: 429-36.

\section{Kawasaki disease}

EDrTor,-We would like to report the possibility of a Koebner phenomenon in Kawasaki disease.' We recently admitted a 20 month old girl with a history of fever for 10 days, cervical lymphadenopathy, bulbar conjunctivitis, and dry fissured lips. She developed an erythematous, polymorphic eruption on the face, limbs, and trunk, and subsequently peeling of the finger tips.
This child had a plaster of Paris splint on the right leg from knee to toes as she was receiving treatment for talipes equinovarus. The child fulfilled the criteria for the diagnosis of Kawasaki disease ${ }^{2}$ and responded to intravenous immunoglobulin and aspirin treatment. During her stay in the ward her plaster was removed at the conclusion of her orthopaedic treatment and we were surprised to find no skin lesions beneath the plaster, though there were linear macular lesions at the edge of the cast where friction had occurred.

This finding suggests that the rash of Kawasaki disease acts as a Koebner or isomorphic phenomenon, with a tendency for the rash to develop at sites of skin trauma or friction. We are unaware of any previous report suggesting this mechanism.

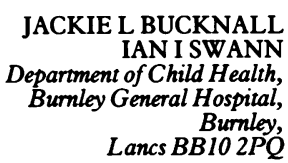

1 Kawasaki T. Acute febrile mucocutaneous syndrome with lymphoid involvement and specific desquamation of the fingers and toes in children. Fapanese foumal of Allergy 1967; 16: 178-222.

2 Levin M, Tizard EJ, Dillon M. Kawasaki disease: recent advances. Arch Dis Child 1991; 66: 1369 